CLINICAL STUDY

\title{
Determinants of cardiac disease in newly diagnosed patients with acromegaly: results of a 10 year survey study
}

\author{
Annamaria Colao, Rosario Pivonello, Ludovica Francesca Stella Grasso, Renata Simona Auriemma, \\ Mariano Galdiero, Silvia Savastano and Gaetano Lombardi \\ Section of Endocrinology, Department of Molecular and Clinical Endocrinology and Oncology, University 'Federico II' of Naples, via S. Pansini 5, \\ 80131 Naples, Italy \\ (Correspondence should be addressed to A Colao; Email: colao@unina.it)
}

\begin{abstract}
Context: The most frequent cause of death in acromegaly is cardiomyopathy. Objective: To evaluate determinants of acromegalic cardiomyopathy.

Design: Observational, open, controlled, retrospective study.

Subjects: Two hundred and five patients with newly diagnosed active acromegaly (108 women and 97 men; median age 44 years) and 410 non-acromegalic subjects sex- and age-matched with the patients. Main outcome measures: Left ventricular (LV) mass index (LVMi), transmitral inflow early-to-atrial (E/A) peak velocity ratio, and LV ejection fraction (LVEF) were measured by Doppler echocardiography to determine the prevalence of LV hypertrophy (LVH), diastolic and systolic dysfunction. The role of age, estimated disease duration, body mass index, GH and IGF1 levels, systolic and diastolic blood pressure, lipid profile and glucose tolerance in determining different features of the acromegalic cardiomyopathy was investigated.

Results: Compared with controls, the patients had lower E/A, LVEF, high-density lipoprotein (HDL)cholesterol levels and higher LVMi, total- and low-density lipoprotein (LDL)-cholesterol, triglycerides, glucose and insulin levels, homeostatic model assessment of insulin resistance (HOMA-R) and HOMA- $\beta$. The relative risk to develop mild (odds ratio $(\mathrm{OR})=1.67(1.05-2.66) ; P=0.027)$ or severe hypertension $(\mathrm{OR}=1.58(1.04-2.32) ; P=0.027)$, arrhythmias $(\mathrm{OR}=4.93(1.74-15.9) ; P=0.001)$, impaired fasting glucose/impaired glucose tolerance $(\mathrm{OR}=2.65(1.70-4.13) ; P<0.0001)$, diabetes $(\mathrm{OR}=2.14$ (1.34-3.40); $P=0.0009)$, LVH $(\mathrm{OR}=11.9$ (7.4-19.5); $P<0.0001)$, diastolic $(\mathrm{OR}=3.32$ (2.09-5.31); $P<0.0001)$ and systolic dysfunction $(\mathrm{OR}=14.2(6.95-32.2) ; P<0.0001)$, was higher in acromegaly. The most important predictor of $\mathrm{LVH}(t=2.4, P=0.02)$ and systolic dysfunction $(t=-2.77$, $P=0.006)$ was disease duration and that of diastolic dysfunction was patient's age $(t=-3.3$, $P=0.001)$. Patients with an estimated disease duration of $>10$ years had a relative risk to present cardiac complications three times higher than patients with estimated disease duration $\leq 5$ years. Conclusions: The prevalence of different features of cardiomyopathy is 3.3-14.2 times higher in the acromegalic than in the non-acromegalic population. The major determinant of cardiomyopathy is disease duration.
\end{abstract}

European Journal of Endocrinology 165 713-721

\section{Introduction}

It is known that patients with uncontrolled acromegaly have an increased mortality of 1.72 (1) to 1.9 (2) compared with those with controlled acromegaly. The main cause of death is cardiovascular disease $(\sim 60 \%)$ while respiratory disease and malignancy account less for mortality (25 and 15\% respectively) (3). The presence of systolic dysfunction at the time of diagnosis is associated with death within 15 years in almost $100 \%$ of cases $(4,5)$.

The acromegalic cardiomyopathy is the heart involvement in the theoretical absence of other cardiac diseases and its most common feature is a concentric biventricular hypertrophy (3). Thickening of cardiac walls is common, but dilation of cardiac chambers is rare because of a relative increase in the cardiac myocytes width for the parallel assembling of new contractile-protein units (3). Postmortem findings reported left ventricular hypertrophy (LVH) in more than $90 \%$ of patients with long disease duration (6). LVH is associated more frequently with diastolic dysfunction and more rarely with systolic dysfunction (3), even in young patients with an estimated short acromegaly duration (7-9). Characteristically, LVH in acromegaly occurs in the absence of arterial hypertension, that is more frequent in acromegaly than in the general population (10), but is further aggravated by it 
(11, 12). Long disease duration is associated with higher prevalence of hypertension and diabetes $(3,13$, $14)$, as well as many other cardiac complications, such as arrhythmias and LV dysfunction (15). However, the risk to develop cardiomyopathy in its different clinical aspects, such as LVH, diastolic and systolic dysfunction, in the acromegalic population compared with the general population and in relation to the estimated disease duration has never been investigated.

This observational, analytical, retrospective, controlled study was designed to investigate determinants of cardiomyopathy in newly diagnosed patients with active acromegaly compared with sex- and age-matched controls of the same geographical area. The role of GH and IGF1 excess and disease duration on the development of echocardiography-demonstrated cardiomyopathy has been studied as the main study outcome. Secondary outcomes were relative to prevalence and severity of hypertension and glucose abnormalities.

\section{Patients and methods}

\section{Inclusion criteria}

Patients with active acromegaly coming to the Unit of Endocrinology of the 'Federico II' University of Naples from January 1st 1997 to December 31st 2009. Criteria upon diagnosis of acromegaly did not vary during the inclusion period, i.e. fasting $\mathrm{GH}$ levels above 2.5 or $1 \mu \mathrm{g} / \mathrm{l}$ after glucose load ( $75 \mathrm{~g}$ per os) in the presence of IGF1 levels above the normal range for age and gender $(16,17)$.

\section{Exclusion criteria}

Patients treated with somatostatin analogues and/or dopamine agonists and/or pegvisomant at the time of diagnosis. Patients were already unsuccessfully operated on.

\section{Patients}

During the study period, of the 257 patients admitted to our department for acromegaly, 52 were excluded because of current medical therapy or after unsuccessful surgery $(n=43)$ or echocardiography data were not available $(n=9)$. Two hundred and five newly diagnosed patients (108 women, aged $46.3 \pm 15.5$ years, median 44 years and 97 men, aged $47.2 \pm 14.8$ years, median 44 years) were enrolled in the study. Magnetic resonance imaging documented microadenoma in 24 (11.7\%); enclosed macroadenomas in 53 (25.8\%); macroadenomas with extrasellar extension in 87 $(42.4 \%)$ and macroadenomas with clear-cut signs of invasion of surrounding structures in 41 patients $(20 \%)$. The presumed duration of acromegaly was assessed by comparing photographs taken over a period of 10-30 years and by interviewing the patients as to the date of onset of acral enlargement and facial disfigurement. The interval between assumed clinical onset and the time of treatment ranged from 2 to 30 years $(9.2 \pm 5.9$ years, median 7.9 years $)$.

\section{Controls}

Four hundred and ten non-acromegalic subjects (216 women and 194 men) were recruited during the same period from the personnel of our University with different health knowledge, lifestyles and jobs (medical doctors, nurses, doctors of biology, laboratory technicians, administrative personnel, cooking personnel, gardeners, cleaning personnel, carpenters, bricklayers, drivers, surveillance personnel, porters and people of the voluntary service). They were matched with the patients for age ( \pm 2 years), gender, and lifestyle. Partial results of the control cohort have previously been reported $(18,19)$. The controls included in this study were not selected for the presence of hypertension, or diabetes or to have information on the prevalence and severity of these complications, if any, but to compare with patients with acromegaly.

All data included in the study derive from a registry approved by our ethics committee (no. 60/97); all subjects gave their informed consent to participate to this registry. All subjects signed an informed consent form to approve diagnostic testing, treatment decision, methods for follow-up and treatment of the data for scientific purposes. This study has been conducted in accordance with the Helsinki II Declaration on human experimentation. The comparison between patients and controls is shown in Table 1.

\section{Study protocol}

At study entry, after an overnight fasting and 3 days of low-fat food intake $(<30 \% ; 7 \%$ saturated fat), the following were measured in all subjects:

1. Serum IGF1 levels twice in a single sample at time 0 of the $\mathrm{GH}$ profile; $\mathrm{GH}$ levels calculated as the mean value of at least 3-6 samples drawn every $30 \mathrm{~min}$ over a period of $2 \mathrm{~h}$.

2. Echocardiography by M-mode, two-dimensional and pulsed Doppler-derived mitral inflow during 3-5 consecutive cardiac cycles as previously reported $(20,21)$ and according to the recommendations of the European Society of Echocardiography (22). The following measurements were determined on M-mode tracing: interventricular septum thickness (IVST), LV internal end-diastolic diameter (LVID) and posterior wall thickness (LVPWT), LV mass (LVM) calculation by the Devereux's formula (23): $\mathrm{LVM}=1.04((\mathrm{IVST}+\mathrm{LVID}+\mathrm{PWT}) 3-$ (LVID)3) $-14 \mathrm{~g}$. LVM indexed for body surface area (LVMi) was $\geq 135 \mathrm{~g} / \mathrm{m}^{2}$ in men and $\geq 110 \mathrm{~g} / \mathrm{m}^{2}$ in women were considered as cut off points for $\mathrm{LVH}$. Diastolic function was evaluated by pulsed Doppler 
Table 1 Profile of patients and controls at study entry.

\begin{tabular}{lccc}
\hline & Patients & Controls & $\boldsymbol{P}$ \\
\hline No. & 205 & 410 & 1 \\
Women/men & $108 / 97$ & $216 / 194$ & 1 \\
Age (years) & $47 \pm 15$ & $46 \pm 19$ & 0.69 \\
Disease duration (months) & $111 \pm 77$ & $/$ & \\
BMI (kg/m ${ }^{2}$ ) & $24.2 \pm 2.9$ & $24.9 \pm 3.4$ & 0.026 \\
GH levels $(\mu \mathrm{g} / \mathrm{l})$ & $52.1 \pm 40.3$ & $0.5 \pm 0.3$ & $<0.0001$ \\
IGF1 levels (ULN) & $2.5 \pm 0.9$ & $0.7 \pm 0.2$ & $<0.0001$ \\
LVMi (g/m ${ }^{2}$ ) & $152.4 \pm 51.5$ & $97.1 \pm 26.0$ & $<0.0001$ \\
E/A ratio & $1.0 \pm 0.2$ & $1.1 \pm 0.1$ & $<0.0001$ \\
LVEF (\%) & $54.6 \pm 7.9$ & $62.6 \pm 7.2$ & $<0.0001$ \\
SBP (mmHg) & $144.6 \pm 19.2$ & $129.0 \pm 19.7$ & $<0.0001$ \\
DBP (mmHg) & $88.2 \pm 10.4$ & $80.4 \pm 7.9$ & $<0.0001$ \\
Heart rate (bpm) & $82.4 \pm 4.7$ & $78.6 \pm 5.8$ & $<0.0001$ \\
Cholesterol (mmol/l) & & & \\
$\quad$ Total & $5.1 \pm 1.1$ & $4.9 \pm 0.8$ & 0.006 \\
$\quad$ LDL & $3.6 \pm 1.1$ & $3.2 \pm 0.9$ & $<0.0001$ \\
HDL & $1.2 \pm 0.2$ & $1.5 \pm 0.2$ & $<0.0001$ \\
Triglycerides levels (mmol/l) & $1.5 \pm 0.4$ & $1.2 \pm 0.4$ & $<0.0001$ \\
Glucose levels (mmol/l) & $5.7 \pm 1.3$ & $5.2 \pm 1.3$ & 0.004 \\
Insulin levels (mU/l) & $26.5 \pm 14.3$ & $9.1 \pm 6.7$ & $<0.0001$ \\
HOMA-R index & $7.1 \pm 5.7$ & $2.4 \pm 2.9$ & $<0.0001$ \\
HOMA- $\beta$ index (\%) & $88.4 \pm 41.2$ & $133.0 \pm 84.7$ & 0.0001 \\
\hline
\end{tabular}

LVMi, left ventricular mass index; LVEF, left ventricular ejection fraction; SBP, systolic blood pressure; DBP, diastolic blood pressue.

$P$ values result from Student's $t$-test analysis; ${ }^{*}$ Data on heart rate refers to 191 patients as 14 had arrhythmias.

mitral inflow as early (E) and atrial (A) peak velocity ratio (E/A), indicating the normal pattern of ventricular diastolic filling when $\geq 1$. LV systolic function was evaluated by ejection fraction (LVEF) normal when $>50 \%$.

3. Total cholesterol, high-density lipoprotein (HDL) cholesterol and triglycerides levels; low-density lipoprotein (LDL)-cholesterol levels were calculated by the formula: $\mathrm{LDL}=$ total-cholesterol $-\mathrm{HDL}$-cholesterol (triglycerides/5). At study entry, hypercholesterolaemia (total cholesterol higher than $5.68 \mathrm{mmol} / \mathrm{l}$ ) was found in 51 patients and 46 controls. Statins were used in 15 patients and 35 controls.

4. Blood pressure, as previously reported (10), and heart rate. The average of six measurements (three taken by each of two examiners) was used in all analysis. According to the seventh report of the Joint National Committee on Prevention, Detection, Evaluation and Treatment of High Blood Pressure (24) the severity of hypertension was classified as mild (Stage 1) when the SBP or DBP were between 140 and $159 \mathrm{mmHg}$ and between 90 and $99 \mathrm{mmHg}$, respectively; severe (Stage 2) when the SBP or DBP were $>160$ and $>100 \mathrm{mmHg}$, respectively; prehypertension was defined as SBP $>120$ to $<140$ and DBP $>80$ to $<90 \mathrm{mmHg}$. At study entry, of the 103 patients and 142 controls with hypertension (Table 2) only 45 $(43.7 \%)$ and $69(48.6 \%)$ received appropriate treatment. Analogous to a previous study (25), angiotensin convertase enzyme (ACE-I) plus calcium channel blockers and diuretics were used in the majority of cases ( 32 and 30 cases, respectively), followed by ACE-I alone (nine and 25 cases, respectively) or associated with diuretics (one and six cases, respectively) and antagonists of the angiotensin-II receptor (three and eight cases respectively).

5. Glucose and insulin levels at fasting. Only in patients with acromegaly and with the exclusion of those with overt diabetes, on diagnosis glucose and insulin were also measured every $30 \mathrm{~min}$ for $2 \mathrm{~h}$ after the oral administration of $75 \mathrm{~g}$ glucose diluted in $250 \mathrm{ml}$ saline solution. Diabetes mellitus was diagnosed when fasting glucose was above $7 \mathrm{mmol} / \mathrm{l}$ $(126 \mathrm{mg} / \mathrm{dl})$ at two consecutive measurements or when $2 \mathrm{~h}$ after the oral glucose tolerance test (oGTT) glucose was $>11 \mathrm{mmol} / \mathrm{l}$ (200 mg/dl) (26). Impaired glucose tolerance (IGT) was diagnosed when glucose level was between $\geq 7.8$ and $<11 \mathrm{mmol} / \mathrm{l} 2 \mathrm{~h}$ after the oGTT while impaired fasting glucose (IFG) was diagnosed when glucose level was between 5.6 and $6.9 \mathrm{mmol} / \mathrm{l}$ at fasting (26). Normal glucose level is now considered when below $5.6 \mathrm{mmol} / \mathrm{l}$ at fasting. To predict insulin resistance (homeostatic model assessment of insulin resistance (HOMA-R) (\%)) and $\beta$-cell function (HOMA- $\beta(\%)$ ) was used the HOMA according with Matthews et al. (27). By assuming that normal weight healthy subjects aged $<35$ years have a HOMA$\beta$ of $100 \%$ and a HOMA-R of 1 , the values for individual patients can be analysed from the insulin and glucose concentrations by the formulae: HOMA-R $=$ (insulin $(\mathrm{mU} / \mathrm{l}) \times$ fasting glucose $(\mathrm{mmol} / \mathrm{l})) / 22.5$; HOMA- $\beta$ $(\%)=(20 \times$ insulin $(\mathrm{mU} / \mathrm{l})) /($ glucose $(\mathrm{mmol} / \mathrm{l})-3.5)$. At study entry of the 47 patients and 50 controls with diabetes (Table 2), only 28 and 33 received appropriate treatment: in detail, metformin alone or associated with glibenclamide was used in 20 and 25 cases, respectively, while insulin was used in the remaining cases.

\section{Assays}

During the study, serum GH levels were measured by IRMA with sensitivity from 0.2 to $0.05 \mu \mathrm{g} / \mathrm{l}$ or chemiluminescence. Serum IGF1 was measured by IRMA after ethanol extraction, using Diagnostic System Laboratories, Inc. (Webster, TX, USA). The normal range changed during the study period. IGF 1 data are shown as the upper limit of normal range ((ULN) normal $=\leq 1$ ). Serum IGF1 levels by IRMA after ethanol extraction using Diagnostic System Laboratories, Inc. The normal ranges for sex and age are reported elsewhere (19).

\section{Statistical analysis}

The data were statistically analysed using MedCalc Software for Windows (MedCalc, Mariakerke, Belgium). Data are reported as mean \pm s.D. unless otherwise 
specified. Comparison between the patients and the controls was made by the Student's $t$-test for unpaired data. The comparison among groups (as for the disease duration analysis) was made by ANOVA. Separately in patients with acromegaly and in controls, we performed first a simple linear regression analysis (Table 3) and then the stepwise multiple linear regression to assess the relative importance of: i) age, body mass index (BMI), serum GH and IGF1 levels (as ULN), patients' disease duration, ii) systolic and diastolic blood pressure and heart rate and iii) total-, LDL- and HDL-cholesterol levels, triglycerides levels, glucose and insulin levels, HOMA-R, HOMA- $\beta$ on LVMi, E/A and LVEF. In this analysis, we entered only those variables that had a $P$ value $<0.01$ in the simple linear regression analysis. We then calculated the relative risk in patients with acromegaly to develop hypertension, lipid and glucose metabolism alterations, LVH, diastolic and systolic dysfunction compared with controls by calculating the observed odds ratio (OR). Data are shown as OR, with the exact Fisher 95\% confidence interval and the twosided $P$ value. This analysis was also made to calculate the relative risk to present $\mathrm{LVH}$, diastolic and systolic dysfunction in patients with long estimated disease duration compared with those with shorter disease duration. This latter analysis was performed after correction for confounding factors.

\section{Results}

Table 1 summarises the characteristics of patients and controls at study entry. Compared with sex- and agematched controls, the patients had lower transmitral $\mathrm{E} / \mathrm{A}$ ratio, HDL-cholesterol levels and higher LVMi, total- and LDL-cholesterol and triglycerides levels, glucose and insulin levels, HOMA-R and HOMA- $\beta$. In analogy, the prevalence of mild and severe hypertension, arrhythmias, glucose abnormalities, LVH, diastolic and systolic dysfunction was higher in patients with acromegaly than in controls (Table 2). The relative risk to develop mild or severe hypertension, arrhythmias, IFG/IGT or diabetes, LVH, diastolic and systolic dysfunction was 1.4-14.2 times higher in the acromegalic than in the non-acromegalic population (Table 2).

Most of the parameters included in the analysis correlated with LVMi, E/A and LVEF (data not shown). Results of the regression analysis are shown in Table 3. In patients with acromegaly and in controls, respectively, disease duration and systolic blood pressure levels were the most important predictor of LVH and systolic dysfunction (Table 4). Diastolic dysfunction was predicted by age and systolic blood pressure respectively. Age was a secondary predictor of $\mathrm{LVH}$, diastolic and systolic dysfunction in controls (Table 4).

As disease duration was the most important predictor of LVH and systolic dysfunction, we analysed the prevalence of these complications in relation to the estimated duration of active acromegaly before diagnosis. The patients were divided into three groups: short disease duration ( $\leq 5$ years), intermediate disease duration (5-10 years) and long disease duration $(>10$ years). There was no difference in BMI, GH and IGF1 levels while, as expected, patients with longer disease duration were older (Table 5). The LVMi was significantly lower in the patients with short disease duration than in those with intermediate and long disease duration, while LVEF was significantly higher in the patients with short disease duration than in the other patients (Table 5). Patients with intermediate disease duration had higher LVEF than the patients with long disease duration. These latter patients also had higher blood pressure levels than the other two groups (Table 5). No other difference was observed in the metabolic profile according with estimated disease duration. The prevalence of $\mathrm{LVH}$, diastolic and systolic dysfunction, as single or combined complication, was significantly lower in the patients with short disease

Table 2 Prevalence of cardiovascular and metabolic complications in patients with acromegaly and in age- and gender-matched controls. Data are present as $n(\%)$ Hypertension, diastolic blood pressure above $90 \mathrm{mmHg}$ (30); diabetes mellitus, fasting glucose $>7 \mathrm{mmol} / \mathrm{l}$ $(126 \mathrm{mg} / \mathrm{dl})$ at two consecutive measurements or $2 \mathrm{~h}$ after the oGTT glucose $\geq 11.1 \mathrm{mmol} / \mathrm{l}(200 \mathrm{mg} / \mathrm{dl})(23)$; impaired glucose tolerance (IGT), impaired fasting glucose (IFG) $<7$ at baseline and between $\geq 7.7 \mathrm{mmol} / \mathrm{l}$ and $<11.1 \mathrm{mg} / \mathrm{dl} 2 \mathrm{~h}$ after the oGTT (25); LV hypertrophy (LVH) was considered when LVM indexed for body surface area (LVMi) was $\geq 135 \mathrm{~g} / \mathrm{m}^{2}$ in men and $\geq 110 \mathrm{~g} / \mathrm{m}^{2}$ in women (21); diastolic dysfunction was diagnosed by an early-to-late mitral flow velocity ratio (E/A) below 1 while systolic dysfunction was diagnosed by a left ventricular ejection fraction below $50 \%(21,22)$.

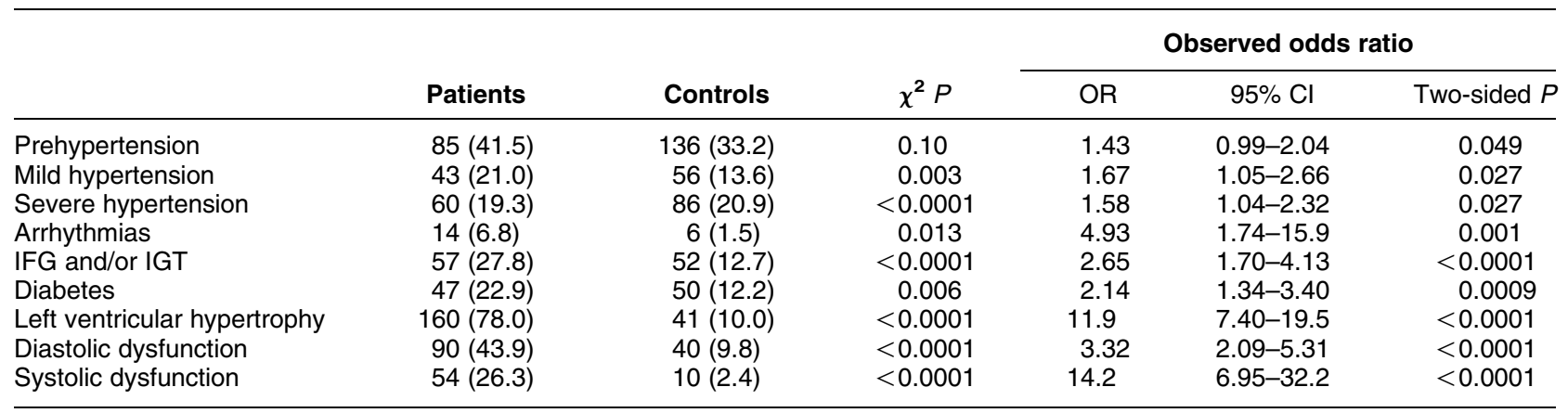


Table 3 Results of the regression analysis.

\begin{tabular}{|c|c|c|c|c|c|c|}
\hline & \multicolumn{2}{|c|}{ LVMi $\left(\mathrm{g} / \mathrm{m}^{2}\right)$} & \multicolumn{2}{|c|}{ MFV } & \multicolumn{2}{|c|}{ LVEF (\%) } \\
\hline & $r$ & $P$ & $r$ & $P$ & $r$ & $P$ \\
\hline \multicolumn{7}{|l|}{ Patients } \\
\hline Age (years) & 0.42 & $<0.0001$ & -0.51 & $<0.0001$ & -0.38 & $<0.0001$ \\
\hline Disease duration (months) & 0.29 & $<0.0001$ & -0.26 & 0.0002 & -0.28 & $<0.0001$ \\
\hline BMI $\left(\mathrm{kg} / \mathrm{m}^{2}\right)$ & 0.21 & 0.003 & 0.16 & 0.019 & 0.00 & 0.94 \\
\hline GH levels $(\mu \mathrm{g} / \mathrm{l})$ & -0.31 & $<0.0001$ & 0.27 & $<0.0001$ & 0.17 & 0.016 \\
\hline IGF1 levels (ULN) & 0.08 & 0.24 & 0.01 & 0.85 & -0.14 & 0.049 \\
\hline Systolic blood pressure (mmHg) & 0.29 & $<0.0001$ & -0.34 & $<0.0001$ & -0.33 & $<0.0001$ \\
\hline Diastolic blood pressure (mmHg) & 0.33 & $<0.0001$ & -0.37 & $<0.0001$ & -0.29 & $<0.0001$ \\
\hline Heart rate $(\mathrm{bpm})^{\mathrm{a}}$ & -0.25 & 0.004 & 0.13 & 0.068 & 0.11 & 0.11 \\
\hline Total cholesterol levels (mmol/l) & 0.12 & 0.081 & -0.18 & 0.008 & -0.24 & 0.0006 \\
\hline LDL-cholesterol levels $(\mathrm{mmol} / \mathrm{l})$ & 0.16 & 0.025 & -0.23 & 0.001 & -0.27 & $<0.0001$ \\
\hline HDL-cholesterol levels (mmol/l) & -0.38 & $<0.0001$ & 0.46 & $<0.0001$ & 0.39 & $<0.0001$ \\
\hline Triglycerides levels $(\mathrm{mmol} / \mathrm{l})$ & 0.32 & $<0.0001$ & -0.35 & $<0.0001$ & -0.31 & $<0.0001$ \\
\hline Glucose levels (mmol/l) & 0.05 & 0.48 & -0.18 & 0.011 & -0.21 & 0.002 \\
\hline Insulin levels (mU/l) & 0.06 & 0.37 & -0.15 & 0.032 & -0.23 & 0.0009 \\
\hline HOMA-R index & 0.07 & 0.32 & -0.16 & 0.02 & -0.25 & 0.0002 \\
\hline HOMA- $\beta$ index & 0.04 & 0.53 & -0.09 & 0.22 & -0.16 & 0.025 \\
\hline \multicolumn{7}{|l|}{ Controls } \\
\hline Age (years) & 0.52 & $<0.0001$ & -0.40 & $<0.0001$ & -0.56 & $<0.0001$ \\
\hline BMl $\left(\mathrm{kg} / \mathrm{m}^{2}\right)$ & 0.47 & $<0.0001$ & -0.27 & 0.001 & -0.55 & $<0.0001$ \\
\hline GH levels $(\mu \mathrm{g} / \mathrm{l})$ & -0.21 & 0.002 & 0.10 & 0.13 & 0.20 & 0.004 \\
\hline IGF1 levels (ULN) & -0.01 & 0.15 & 0.00 & 0.94 & 0.07 & 0.33 \\
\hline Systolic blood pressure (mmHg) & 0.84 & $<0.0001$ & -0.63 & $<0.0001$ & -0.71 & $<0.0001$ \\
\hline Diastolic blood pressure $(\mathrm{mmHg})$ & 0.67 & $<0.0001$ & -0.47 & $<0.0001$ & -0.55 & $<0.0001$ \\
\hline Heart rate $(\mathrm{bpm})$ & 0.15 & 0.031 & -0.10 & 0.35 & -0.04 & 0.54 \\
\hline Total cholesterol levels (mmol/l) & 0.54 & $<0.0001$ & -0.45 & $<0.0001$ & -0.55 & $<0.0001$ \\
\hline LDL-cholesterol levels ( $\mathrm{mmol} / \mathrm{l})^{\prime}$ & 0.56 & $<0.0001$ & -0.46 & $<0.0001$ & -0.57 & $<0.0001$ \\
\hline HDL-cholesterol levels (mmol/l) & -0.49 & $<0.0001$ & 0.38 & $<0.0001$ & 0.49 & $<0.0001$ \\
\hline Triglycerides levels $(\mathrm{mmol} / \mathrm{l})$ & 0.54 & $<0.0001$ & -0.44 & $<0.0001$ & -0.56 & $<0.0001$ \\
\hline Glucose levels $(\mathrm{mmol} / \mathrm{l})$ & 0.53 & $<0.0001$ & -0.45 & $<0.0001$ & -0.57 & $<0.0001$ \\
\hline Insulin levels (mU/l) & 0.38 & $<0.0001$ & -0.34 & $<0.0001$ & -0.43 & $<0.0001$ \\
\hline HOMA-R index & 0.59 & $<0.0001$ & -0.3 & $<0.0001$ & -0.41 & $<0.0001$ \\
\hline HOMA- $\beta$ index & -0.21 & 0.002 & 0.15 & 0.024 & 0.19 & 0.005 \\
\hline
\end{tabular}

LVMi, left ventricular mass index; MFV, early-to-late mitral flow velocity; LVEF, left ventricular ejection fraction.

${ }^{\mathrm{a}}$ Fourteen of the 205 patients had arrhythmias.

duration, than in those with intermediate disease duration who had a significantly lower prevalence than those with long disease duration (Fig. 1).

Patients with estimated disease duration longer than 10 years before diagnosis had a relative risk to present LVH 9.9 times, diastolic dysfunction 4.8 times and all cardiac complications three times higher than patients with estimated disease duration shorter than 10 years months (Fig. 2). Conversely, the prevalence of systolic dysfunction was only modestly, but not significantly, higher in the patients with longer disease history.

\section{Discussion}

At variance with all previous papers, this study included a very large series of patients and controls to make a statistically valid analysis of risk factors for cardiomyopathy due to GH and IGF1 excess. The most important finding of the current observational, retrospective, controlled study is that the duration of active acromegaly before diagnosis as estimated by characteristic changes in the physiognomy of the patients on photographs is the major determinant of prevalence and severity of cardiomyopathy. Patients with estimated disease duration longer than 10 years, had an average relative risk to present $\mathrm{LVH}$ associated with diastolic and systolic dysfunction three times higher than those with shorter disease duration. The most striking difference was in the prevalence of LVH that was approximately ten times higher in patients with long disease duration than in the other patients. This effect could be due to both the longer duration of GH and IGF1 excess on cardiomyocytes and to the higher blood pressure levels in patients with longer disease duration. This study extends in a large series the demonstration that prevalence of arterial hypertension (both mild and severe hypertension), arrhythmias, glucose abnormalities and cardiac dysfunction is significantly higher in acromegalic patients than in non-acromegalic subjects. Thanks to the large series of non-acromegalic control subjects, we could estimate the relative risk to develop different aspect of cardiomyopathy in patients with acromegaly. These data agree with those published by a 
Table 4 Results of the stepwise regression analysis.

\begin{tabular}{|c|c|c|c|c|c|c|}
\hline & \multicolumn{2}{|c|}{ LVMi $\left(\mathrm{g} / \mathrm{m}^{2}\right)$} & \multicolumn{2}{|c|}{ MFV } & \multicolumn{2}{|c|}{ LVEF (\%) } \\
\hline & $t$ & $P$ & $t$ & $P$ & $t$ & $P$ \\
\hline \multicolumn{7}{|l|}{ Patients } \\
\hline DD (years) & 2.4 & 0.02 & & & -2.77 & 0.006 \\
\hline Age (years) & 2.3 & 0.02 & -3.3 & 0.001 & & \\
\hline $\mathrm{HDL}(\mu \mathrm{g} / \mathrm{l})$ & & & 2.1 & 0.03 & & \\
\hline \multicolumn{7}{|l|}{ Controls } \\
\hline $\mathrm{SBP}(\mathrm{mmHg})$ & 10.1 & $<0.0001$ & -5.3 & $<0.0001$ & -5.8 & $<0.0001$ \\
\hline Age (years) & 2.8 & 0.005 & -2.4 & 0.02 & -4.4 & $<0.0001$ \\
\hline BMI $\left(\mathrm{kg} / \mathrm{m}^{2}\right)$ & & & & & -2.6 & 0.009 \\
\hline Insulin levels & U/I) & & & & -2.3 & 0.002 \\
\hline
\end{tabular}

LVMi, left ventricular mass index; MF, MFV, early-to-late mitral flow velocity; LVEF, left ventricular ejection fraction; DD, disease duration; HDL, high density lipoprotein cholesterol.

recent German registry study showing a higher cardiovascular risk in patients with acromegaly (as measured by the Framingham model) compared with the control population (28).

However, it should be mentioned, however, that the control group we have used might present a methodology bias as we had the opportunity to perform a complete cardiac and endocrine screening in a selected group of subjects coming to the clinic for various reasons. Even if none of the recruited subjects were selected on the basis of any of the parameters relevant for this study, we cannot rule out the possibility that our control group does not fully represent the general worldwide population. Nevertheless, recruitment of non-acromegalic subjects was made in the effort of providing an unbiased group of subjects coming from the same geographical area, in the same period of time of our patients and without any selection as for cardiovascular disease, working habits and lifestyle. Data on epidemiology of cardiovascular risk factor in the Southern Italian population reports prehypertension in $15 \%$, mild or severe hypertension in 33\%, diabetes in $9 \%$, IGT in $7 \%$, LVH in $1.5 \%$ and atrial fibrillation in 1\% (29). Thus, the prevalence of glucose tolerance alterations and hypertension observed in our controls was in line with the epidemiological evidence, while LVH was higher than expected, probably emphasised by routine echocardiography. By considering the drawbacks mentioned, the inclusion of a control group allowed us to calculate the relative risk of patients with acromegaly to develop cardiovascular complications, thus providing an approximate risk of disease.

The calculation of the approximate risk of cardiac disease in acromegaly is relevant since cardiac disease is considered as an independent risk for premature death in patients with acromegaly together with elevated GH and IGF1 levels and hypertension (1-3). In contrast, other complications such as glucose abnormalities or cancer are reportedly less important determinants of mortality (5). Increased LVM is a premier risk factor for cardiovascular disease events (30) and acromegaly is a disease with a well known increased risk to develop LVH (31). The relative risk of patients with acromegaly to present LVH is at least 11.9 times higher than sex- and age-matched non-acromegalic subjects. This high risk to develop LVH is clinically relevant as concentric

Table 5 Effect of estimated disease duration on systemic complications of acromegaly.

\begin{tabular}{|c|c|c|c|c|}
\hline & \multicolumn{3}{|c|}{ Estimated disease duration } & \multirow[b]{2}{*}{$P$} \\
\hline & $<5$ years & $5-10$ years & $>10$ years & \\
\hline$n$ & 73 & 87 & 45 & \\
\hline Women/men & $44 / 29$ & $43 / 44$ & $21 / 24$ & 0.8 \\
\hline Age (years) & $42 \pm 14$ & $48 \pm 14$ & $53 \pm 16$ & $<0.0001$ \\
\hline BMI $\left(\mathrm{kg} / \mathrm{m}^{2}\right)$ & $24.4 \pm 3.4$ & $24.1 \pm 2.5$ & $24.1 \pm 2.5$ & 0.75 \\
\hline GH levels $(\mu \mathrm{g} / \mathrm{l})$ & $59.2 \pm 47.8$ & $52.1 \pm 37.0$ & $40.6 \pm 30.1$ & 0.051 \\
\hline IGF1 levels (ULN) & $2.4 \pm 0.8$ & $2.6 \pm 1.1$ & $2.6 \pm 0.8$ & 0.35 \\
\hline LVMi $\left(\mathrm{g} / \mathrm{m}^{2}\right)$ & $133.2 \pm 34.3^{\star, \dagger}$ & $159.3 \pm 55.6$ & $170.3 \pm 57.5$ & $<0.0001$ \\
\hline E/A ratio & $1.1 \pm 0.2$ & $1.0 \pm 0.2$ & $0.9 \pm 0.2$ & 0.76 \\
\hline LVEF (\%) & $56.6 \pm 6.7^{\dagger}$ & $54.2 \pm 7.7$ & $52.0 \pm 9.2$ & 0.007 \\
\hline SBP $(\mathrm{mmHg})$ & $140.4 \pm 19.7^{\dagger}$ & $145.1 \pm 18.3$ & $151.1 \pm 18.8$ & 0.01 \\
\hline $\mathrm{DBP}(\mathrm{mmHg})$ & $84.6 \pm 8.6^{\star, \dagger}$ & $80.4 \pm 7.9^{\dagger}$ & $93.1 \pm 11.2$ & $<0.0001$ \\
\hline Heart rate $(\mathrm{bpm})^{\mathrm{a}}$ & $82.8 \pm 4.7$ & $82.2 \pm 10.4$ & $82.2 \pm 3.5$ & 0.87 \\
\hline \multicolumn{5}{|l|}{ Cholesterol (mmol/l) } \\
\hline Total & $5.2 \pm 0.9$ & $5.2 \pm 1.2$ & $5.0 \pm 0.9$ & 0.55 \\
\hline LDL & $3.7 \pm 1.0$ & $3.7 \pm 1.3$ & $3.5 \pm 0.9$ & 0.57 \\
\hline HDL & $1.2 \pm 0.2$ & $1.2 \pm 0.2$ & $1.2 \pm 0.2$ & 1.0 \\
\hline Triglycerides levels $(\mathrm{mmol} / \mathrm{l})$ & $1.5 \pm 0.4$ & $1.5 \pm 0.5$ & $1.6 \pm 0.4$ & 0.41 \\
\hline Glucose levels (mmol/l) & $5.6 \pm 0.9$ & $5.7 \pm 1.5$ & $5.9 \pm 1.4$ & 0.47 \\
\hline Insulin levels (mU/l) & $24.0 \pm 11.0$ & $27.2 \pm 15.9$ & $28.6 \pm 15.5$ & 0.18 \\
\hline HOMA-R index & $6.1 \pm 3.1$ & $7.4 \pm 6.9$ & $8.0 \pm 6.3$ & 0.17 \\
\hline HOMA- $\beta$ index & $83.0 \pm 39.6$ & $90.8 \pm 42.3$ & $92.5 \pm 41.9$ & 0.37 \\
\hline
\end{tabular}

LVMi, left ventricular mass index; LVEF, left ventricular ejection fraction; SBP, systolic blood pressure; DBP, diastolic blood pressure. $P$ values result from ANOVA. ${ }^{*} P<0.05$ versus patients with disease duration $5-10$ years; ${ }^{\dagger} P<0.05$ versus patients with disease duration $>10$ years.

${ }^{\mathrm{a}}$ In the three groups of numbers were 70,82 and 39 
hypertrophy has been shown to be the major determinant of cardiac stroke in a multiethnic study (32). No data are available on the prevalence of asymptomatic diastolic and systolic dysfunction in the general population. However, in comparison with our controls, patients with acromegaly have a risk to present diastolic or systolic dysfunction at diagnosis at least 3.3 and 14.2 times higher. As an additional result of this study, we have shown that patients with acromegaly have a relative risk to present hypertension (1.4-1.7 times), arrhythmias (4.9 times) and glucose alterations (IGT 2.6 and diabetes 2.1 times) higher than the general population.

In a previous multicentre study, we demonstrated a significant negative effect of hypertension on prevalence of LVH (12), analogous previous results of López-Velasco et al. (11). Less understood is the role of insulin resistance in further increasing cardiac mass in acromegaly. No significant additive effect of glucose impairment was shown in our previous study (12) though considerable clinical evidence supports a role for insulin resistance in the pathogenesis of LVH (33). However, as shown by the regression analysis, neither in the patients nor in the controls, insulin levels appeared to be the major predictor of LVM. Thus, we can conclude that glucose abnormalities and insulin resistance display a minor role in determining the severity of cardiomyopathy. It is possible that, at cardiomyocytes level, chronic excess of IGF1 overcomes the effects of elevated insulin levels, but no molecular studies are available to further demonstrate this issue.

It is interesting that in the patients' group, the estimated disease duration was the major predictor of LVH and LVEF as surrogate measure of systolic function. Anyway, the approximate risk to present diastolic or systolic dysfunction in the patients population was at least 3.3 and 14.2 times higher than our control population. This clearly confers an increased risk to develop fatal cardiovascular events to the acromegalic population (1-3). In previous studies enrolling smaller series of patients with acromegaly $(11,12)$, the effect of estimated disease duration was not statistically

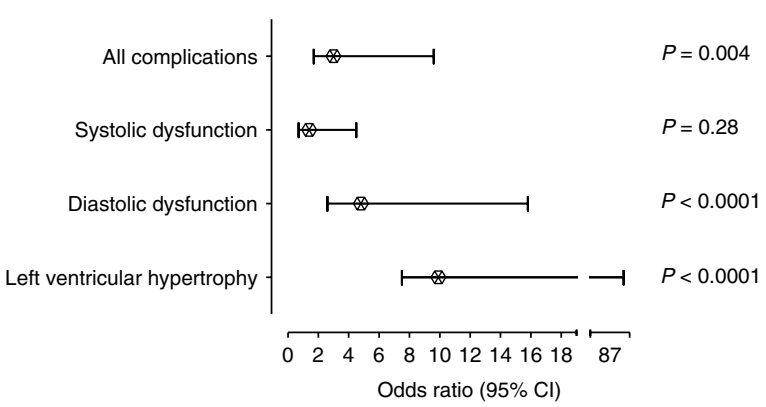

Figure 1 Prevalence of left ventricular hypertrophy, diastolic and systolic dysfunction and of a combination of these complications at diagnosis of acromegaly in relation to estimated disease duration.

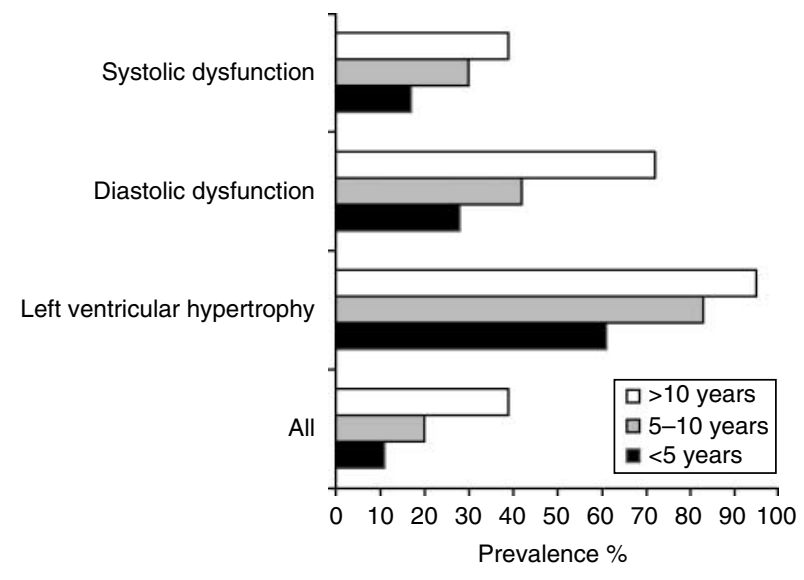

Figure 2 Calculation of the odds ratio for the presence of left ventricular hypertrophy, diastolic and systolic dysfunction and a combination of these complications in patients with estimated duration of acromegaly $\geq 10$ years compared with those with estimated disease duration $<10$ years.

significant clearly due to the wide distribution of this parameter. Another recent study, comparing 133 patients with acromegaly and 665 controls (28) also showed increased prevalence of hypertension and diabetes as well as increased Framingham Risk Score in the patients, with relative risk in the patients with acromegaly similar to those found in our patients. However, in this study there was no data on echocardiography. In this study, because of inclusion of rather large series of patients subjected to echocardiography on diagnosis as part of our routine clinical practice since 1997, we could demonstrate that patients with estimated disease duration longer than 12 years had a risk presenting LVH 9.9 times higher and diastolic dysfunction by 4.8 times higher than those receiving diagnosis of acromegaly after a period of time shorter than 5 years.

\section{Conclusion}

The results of the current analytical, observational, retrospective, controlled study demonstrate that patients with acromegaly have a high risk to develop cardiac complications, hypertension, arrhythmias and glucose abnormalities. The risk is extremely high for patients who are diagnosed with a delay of more than 10 years from the start of the disease. Due to the well-established epidemiological evidence that patients with acromegaly have a reduced life expectancy because of cardiac disease, all effort should be made to diagnose this disease as early as possible. National Health Institutions should be made aware of this clinical problem and improve awareness in family doctors who are the first medical contact of patients with acromegaly. As control of GH and IGF1 excess is associated with a decrease in cardiovascular risk $(3,20,21,28,31,34,35)$, successful treatment is mandatory in patients with acromegaly. 


\section{Declaration of interest}

The authors declare that there is no conflict of interest that could be perceived as prejudicing the impartiality of the research reported.

\section{Funding}

This study did not receive any specific financial support. The section of Endocrinology of the Department of Molecular and Clinical Endocrinology and Oncology, University 'Federico II' of Naples receives unrestricted grants from Ipsen, Italfarmaco, Novartis and Pfizer for research studies in acromegaly.

\section{Acknowledgements}

The echocardiographic data included into the study were provided by Letizia Spinelli (Department of Internal Medicine) and Maurizio Galderisi (Department of Clinical and Experimental Medicine) University Federico II of Naples. The authors thank their availability in participating in the study of cardiovascular impact of endocrine diseases. We also thank Dr Carolina Di Somma, IRCCS SDN Foundation Naples, for her valuable help in performing the statistical analysis included in the study.

\section{References}

1 Dekkers OM, Biermasz NR, Pereira AM, Romijn JA \& Vandenbroucke JP. Mortality in acromegaly: a metaanalysis. Journal of Clinical Endocrinology and Metabolism 200893 61-67. (doi:10.1210/jc. 2007-1191)

2 Holdaway IM, Bolland MJ \& Gamble GD. A meta-analysis of the effect of lowering serum levels of GH and IGF-I on mortality in acromegaly. European Journal of Endocrinology 2008159 89-95. (doi:10.1530/EJE-08-0267)

3 Colao A, Ferone D, Marzullo P \& Lombardi G. Systemic complications of acromegaly: epidemiology, pathogenesis, and management. Endocrine Reviews 200425 102-152. (doi:10. 1210/er.2002-0022)

4 Rajasoorya C, Holdaway IM, Wrightson P, Scott DJ \& Ibbertson HK. Determinants of clinical outcome and survival in acromegaly. Clinical Endocrinology 199441 95-102. (doi:10.1111/j.13652265.1994.tb03789.x)

5 Melmed S. Acromegaly and cancer: not a problem. Journal of Clinical Endocrinology and Metabolism $2001 \quad 862929-2934$. (doi:10.1210/jc.86.7.2929)

6 Lie JT \& Grossman SJ. Pathology of the heart in acromegaly: anatomic findings in 27 autopsied patients. American Heart Journal 1980100 41-52. (doi:10.1016/0002-8703(80)90277-X)

7 Minniti G, Jaffrain-Rea ML, Moroni C, Baldelli R, Ferretti E Cassone R, Gulino A \& Tamburrano G. Echocardiographic evidence for a direct effect of GH/IGF-I hypersecretion on cardiac mass and function in young acromegalics. Clinical Endocrinology 199849 101-106. (doi:10.1046/j.1365-2265.1998.00493.x)

8 Colao A, Cuocolo A, Marzullo P, Nicolai E, Ferone D, Della Morte AM, Petretta M, Salvatore M \& Lombardi G. Impact of patient's age and disease duration on cardiac performance in acromegaly: a radionuclide angiography study. Journal of Clinical Endocrinology and Metabolism 199984 1518-1523. (doi:10. 1210/jc.84.5.1518)

9 Colao A, Spinelli L, Cuocolo A, Spiezia S, Pivonello R, di Somma C, Bonaduce D, Salvatore M \& Lombardi G. Cardiovascular consequences of early-onset growth hormone excess. Journal of Clinical Endocrinology and Metabolism 200287 3097-3104. (doi:10.1210/jc.87.7.3097)

10 Vitale G, Pivonello R, Auriemma RS, Guerra E, Milone F, Savastano S, Lombardi G \& Colao A. Hypertension in acromegaly and in the normal population: prevalence and determinants. Clinical Endocrinology 200563 470-476. (doi:10.1111/j.13652265.2005.02370.x)

11 López-Velasco R, Escobar-Morreale HF, Vega B, Villa E, Sancho JM, Moya-Mur JL \& Garcia-Robles R. Cardiac involvement in acromegaly: specific myocardiopathy or consequence of systemic hypertension. Journal of Clinical Endocrinology and Metabolism 199782 1047-1053. (doi:10.1210/jc.82.4.1047)

12 Colao A, Baldelli R, Marzullo P, Ferretti E, Ferone D, Gargiulo P, Petretta M, Tamburrano G, Lombardi G \& Liuzzi A. Systemic hypertension and impaired glucose tolerance are independently correlated to the severity of the acromegalic cardiomyopathy. Journal of Clinical Endocrinology and Metabolism 200085 193199. (doi:10.1210/jc.85.1.193)

13 Resmini E, Minuto F, Colao A \& Ferone D. Secondary diabetes associated with principal endocrinopathies: the impact of new treatment modalities. Acta Diabetologica 200946 85-95. (doi:10. 1007/s00592-009-0112-9)

14 Jayasena C, Comninos A, Clarke H, Donaldson M, Meeran K \& Dhillo $W$. The effects of long term GH and IGF-1 exposure on the development of cardiovascular, cerebrovascular and metabolic co-morbidities in treated patients with acromegaly. Clinical Endocrinology 201175 220-225. (doi:10.1111/j.1365-2265. 2011.04019.x)

15 Colao A, Pivonello R, Spinelli L, Galderisi M, Auriemma RS, Galdiero M, Vitale G, De Leo M \& Lombardi G. A retrospective analysis on biochemical parameters, cardiovascular risk and cardiomyopathy in elderly acromegalic patients. Journal of Endocrinological Investigation $2007 \mathbf{3 0} 497-506$.

16 Colao A \& Lombardi G. Growth-hormone and prolactin excess. Lancet 1998352 1455-1461. (doi:10.1016/S01406736(98)03356-X)

17 Giustina A, Barkan A, Casanueva FF, Cavagnini F, Frohman L, Ho K, Veldhuis J, Wass J, Von Werder K \& Melmed S. Criteria for cure of acromegaly: a consensus statement. Journal of Clinical Endocrinology and Metabolism 200085 526-529. (doi:10.1210/ jc.85.2.526)

18 Colao A, Spiezia S, Di Somma C, Pivonello R, Marzullo P, Rota F, Musella T, Auriemma RS, De Martino MC \& Lombardi G. Circulating insulin-like growth factor-I levels are correlated with the atherosclerotic profile in healthy subjects independently of age. Journal of Endocrinological Investigation $2005 \mathbf{2 8} 440-448$.

19 Colao A, Di Somma C, Cascella T, Pivonello R, Vitale G, Grasso LF, Lombardi G \& Savastano S. Relationships between serum IGF1 levels, blood pressure, and glucose tolerance: an observational, exploratory study in 404 subjects. European Journal of Endocrinology 2008159 389-397. (doi:10.1530/EJE-08-0201)

20 Colao A, Marzullo P, Ferone D, Spinelli L, Cuocolo A, Bonaduce D, Salvatore M, Boerlin V, Lancranjan I \& Lombardi G. Cardiovascular effects of depot long-acting somatostatin analog Sandostatin LAR ${ }^{\circledR}$ in acromegaly. Journal of Clinical Endocrinology and Metabolism 200086 3132-3140. (doi:10.1210/jc.85.9.3132)

21 Colao A, Marzullo P, Cuocolo A, Spinelli L, Landi ML, Bonaduce D, Salvatore M \& Lombardi G. Reversal of acromegalic cardiomyopathy in young but not in middle-aged patients after 12 months of treatment with the depot long-acting somatostatin analogue Octreotide. Clinical Endocrinology 200358 169-176. (doi:10. 1046/j.1365-2265.2003.01689.x)

22 Evangelista A, Flachskampf F, Lancellotti P, Badano L, Aguilar R, Monaghan M, Zamorano J \& Nihoyannopoulos P \& European Association of Echocardiography. European Association of Echocardiography recommendations for standardization of performance, digital storage and reporting of echocardiographic studies. European Journal of Echocardiography 20089 438-444. (doi:10.1093/ejechocard/jen174)

23 Devereux RB. Detection of left ventricular hypertrophy by M-mode echocardiography. Anatomic validation, standardization, and comparison to other methods. Hypertension 19879 (Suppl 2) 19-26.

24 Chobanian AV, Bakris GL, Black HR, Cushman WC, Green LA, Izzo JL Jr, Jones DW, Materson BJ, Oparil S, Wright JT Jr, Roccella EJ, 
and the National High Blood Pressure Education Program Coordinating Committee. The seventh report of the joint National Committee on prevention, detection, evaluation and treatment of high blood pressure. Journal of the American Medical Association 2003289 2560-2561. (doi:10.1001/jama.289.19.2560)

25 Colao A, Terzolo M, Bondanelli M, Galderisi M, Vitale G, Reimondo G, Ambrosio MR, Pivonello R, Lombardi G, Angeli A \& degli Uberti EC. GH and IGF-I excess control contributes to blood pressure control: results of an observational, retrospective, multicentre study in 105 hypertensive acromegalic patients on hypertensive treatment. Clinical Endocrinology $200869613-620$. (doi:10.1111/j.1365-2265.2008.03258.x)

26 American Diabetes Association. Diagnosis and classification of diabetes mellitus. Diabetes Care 200629 S43-S48.

27 Matthews DR, Hosker JP, Rudenski AS, Naylor BA, Treacher DF \& Turner RC. Homeostasis model assessment: insulin resistance and $\beta$-cell function from fasting plasma glucose and insulin concentrations in man. Diabetologia $1985 \mathbf{2 8}$ 412-419. (doi:10.1007/ BF00280883)

28 Berg C, Petersenn S, Lahner H, Herrmann BL, Buchfelder M, Droste M, Stalla GK, Strasburger CJ, Roggenbuck U, Lehmann N, Moebus S, Jöckel K-H, Möhlenkamp S, Erbel R, Saller B \& Mann K \& on behalf of the Investigative Group of the Heinz Nixdorf Recall Study and the German Pegvisomant Observational Study Board and Investigators*. Cardiovascular risk factors in patients with uncontrolled and long-term acromegaly: comparison with matched data from the general population and the effect of disease control. Journal of Clinical Endocrinology and Metabolism 201095 3648-3656. (doi:10.1210/jc.2009-2570)

29 The Italian cardiovascular epidemiological observatory of the Superior Institute of Health. Italian Heart Journal 20045 (Suppl 3) 49S-95S.
30 Di Tullio MR, Zwas DR, Sacco RL, Sciacca RR \& Homma S. Left ventricular mass and geometry and risk of ischemic stroke. Stroke 200334 2380-2386. (doi:10.1161/01.STR.0000089 680.77236.60)

31 Colao A. The GH-IGF-I axis and the cardiovascular system: clinical implications. Clinical Endocrinology $200869347-358$. (doi:10.1111/j.1365-2265.2008.03292.x)

32 Levy D, Garrison RJ, Savage DD, Kannel WB \& Castelli WP. Prognostic implications of echocardiographically determined left ventricular mass in the Framingham Heart Study. New England Journal of Medicine $1990 \mathbf{3 2 2}$ 1561-1566. (doi:10.1056/ NEJM199005313222203)

33 Rutter MK, Parise H, Benjamin EJ, Levy D, Larson MG, Meigs JB, Nesto RW, Wilson PW \& Vasan RS. Impact of glucose intolerance and insulin resistance on cardiac structure and function: sex-related differences in the Framingham Heart Study. Circulation 2003107 448-454. (doi:10.1161/01.CIR.0000045671.62860.98)

34 Maison P, Tropeano AI, Macquin-Mavier I, Giustina A \& Chanson P. Impact of somatostatin analogs on the heart in acromegaly: a metaanalysis. Journal of Clinical Endocrinology and Metabolism 2007 92 1743-1747. (doi:10.1210/jc.2006-2547)

35 Pivonello R, Galderisi M, Auriemma RS, De Martino MC, Galdiero M, Ciccarelli A, D'Errico A, Kourides I, Burman P, Lombardi G \& Colao A. Treatment with growth hormone receptor antagonist in acromegaly: effect on cardiac structure and performance. Journal of Clinical Endocrinology and Metabolism 200792 476-482. (doi:10.1210/jc.2006-1587)

Received 8 May 2011

Revised version received 24 August 2011

Accepted 25 August 2011 